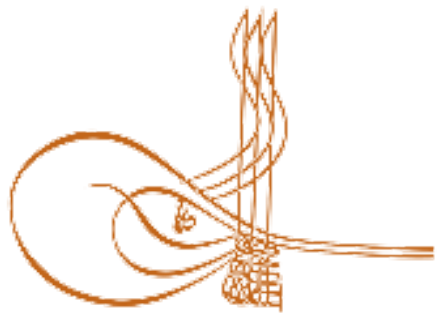

www.turkishstudies.net/education
Turkish Studies - Educational Sciences

eISSN: $2667-5609$

Research Article / Araștırma Makalesi

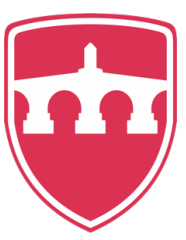

INTERNATIONAL

BALKAN

UNIVERSITY

Sponsored by IBU

\title{
Sosyal Bilgiler Öğretmen Adaylarının Öğretmen Kavramına İlişkin İleri Sürdükleri Metaforlar
}

\author{
The Metaphors of Social Studies Teacher Candudates about the Concept of Teacher
}

\author{
İskender Daşdemir ${ }^{*}-$ Aylin Mentiş Köksoy ${ }^{* *}$
}

\begin{abstract}
Key In this study, it was aimed to reveal the perceptions, perspectives, and subjective opinions of social studies teacher candidates about the concept of teacher, and the meanings they placed on the concept of teacher. The general aim of the research, which is set out for these purposes, is to examine the perceptions of social studies teacher candidates about the concept of teacher through metaphors. In line with this general purpose, the following questions were sought in the research: What are the metaphors that social studies teacher candidates have regarding the concept of teacher? Under which categories can the metaphors put forward by the social studies teacher candidates regarding the concept of teacher be collected in terms of their common characteristics? The research is methodologically a qualitative research. The study group of the study consisted of 41 senior social studies teachers who studied at the Ege University Faculty of Education Social Sciences Teaching Department in the Fall Term of 2019-2020 and agreed to participate in the research. In order to collect data in the research, it is like "Teacher ........" on students. Because the forms with the expression .......... "have been distributed and asked to complete the statement on the form. Then, the forms were written by the students' own statements, and content analysis was performed on the data obtained. By examining the statements completed by the students, the papers of five students who did not make any reasoned explanation were excluded. The analysis of the data took place in four stages, naming, screening, categorizing and ensuring validity and reliability. As a result of the analysis of the data, 36 metaphors created by prospective teachers were collected under three categories. By interpreting the collected topics, it was attempted to reveal the motophoric perspectives of teacher candidates on social studies.
\end{abstract}

*Ögr. Gör. Dr., Ege Üniversitesi, Eğitim Fakültesi, Türkçe ve Sosyal Bilimler Bölümü Lecturer Dr., Ege University, Faculty of Education, Turkish and Social Sciences Department ORCID 0000-0003-4158-2388

**Doç. Dr., Ege Üniversitesi, Eğitim Fakültesi, Temel eğitim Bölümü

Assoc. Prof. Dr. Ege University, Faculty of Education, Department of Basic Education ORCID 0000-0003-4549-0579

Cite as/ Atıf: Daşdemir, İ \& Mentiş Köksoy, A. (2020). Sosyal bilgiler öğretmen adaylarının öğretmen kavramına ilişkin ileri sürdükleri metaforlar, Turkish Studies-Education, 15(2), 751-763. https://dx.doi.org/10.29228/TurkishStudies.39727

Received/Geliş: 13 November/Kasım 2019

Accepted/Kabul: 30 April/Nisan 2020

Copyright C INTAC LTD, Turkey

Checked by plagiarism software

Published/Yayın: 30 April/Nisan 2020

CC BY-NC 4.0 
Structured Abstract: In this study, it was aimed to determine the perceptions of social science teacher candidates about the concept of "teacher" through metaphors. In line with this general purpose, the following questions were sought in this study.

1. What are the metaphors that social studies teacher candidates have regarding the concept of teacher?

2. Under which categories can the metaphors proposed by the teacher candidates regarding the concept of teacher be collected in terms of their common characteristics?

In this research, the phenomenology pattern, which is one of the qualitative research methods, was used. The phenomenon of science focuses on the cases that we are aware of but do not have intensity and detailed thought. For studies that aim to investigate cases that are not entirely foreign to us, but whose meaning we cannot fully comprehend, phenomenology creates a favorable research basis.

The study group of the study consisted of 41 senior students studying in Ege University, Faculty of Education, Department of Social Studies Education in the fall semester of 2019-2020.To determine the metaphors of social studies teacher candidates about the concept of "Teacher", it is like "Teacher..." on the participants. Because... Forms with the expression "have been distributed and asked to complete the statement on the form. At the beginning of the study, pre-service teachers were explained with the examples of the concept of "metaphor" and 20 minutes were given to produce metaphors suitable for this sentence and write the reasons for choosing this metaphor.

The analysis of the data took place in four stages: naming, screening, categorizing, and ensuring validity and reliability (Saban, 2008). The forms filled by the students were numbered as Ö1, Ö2 (Student1, Student2). Metaphors produced by students are coded according to the number. In the second stage, the papers completed by the students were examined and the papers of five students who did not make reasoned explanations were excluded. Justification was given and 36 valid metaphors were obtained. In the third stage, the statements completed by the students were revised. Metaphors created by students are examined in terms of their common features. 36 valid metaphors are gathered under three categories in terms of their common features and reasons for justification. In the fourth stage, in order to ensure the validity of the research results, how the data analysis process was conducted was explained and the metaphors obtained in the research were included. In addition, the findings section includes examples that are thought to best express each of the 3 categories created for 36 metaphors. To ensure the reliability of the research, the consistency in the coding made by the researcher at two different times was examined in order to determine whether the metaphors under the three categories were collected under those categories. For this, the researcher coded for the second time at 15-day intervals and tested his own consistency. Reliability = consensus / consensus + opinion disagreement formula (Miles \& Huberman, 1994) was used and coding reliability coefficient of consistency was calculated as. 90 .

Social studies teacher candidates produced 36 metaphors about the concept of teacher. These metaphors are gathered under 3 categories under the headings that illuminate, shape / direction and labor, and give taste and peace. Based on these findings, it can be said that social studies teacher candidates see the concept of teacher as important in their lives and have very positive meanings to the concept of teacher. Results revealed in the study It was observed that the pre-service teachers perceive the concept of teacher as a lantern, a burning candle, sun, book, novel, information source, tourist guide, carpenter, mother, floor signpost. Ertürk (2017), in his study, where the students explain their teachers with the parent metaphor, after the study carried out by Saban (2004), the pre-service teachers see the teachers as a sculptor, Çelikten (2006), Gillis and Jonhson (2002), Cerit (2008), Turhan and Yaraş. (2013), according to the results of his studies, the explanation of the concept of teacher with known metaphors such as farmer, gardener, tree, Google, computer, light, lantern, book is similar to the results of this study. Saban (2006), in his study, students describe the concept of teacher as a source of information, Aydın and Pehlivan (2010) regard students as a source of knowledge, Koç (2014), in their study, seeing the concept of teacher as a source of information and sacrifice, Kalyoncu (2012) also in his study. It was seen that the students attributed meaning to the concept of teacher as educator, instructor and guide. In the studies of Yıldırım, Ünal and Çelik (2011), Özdemir (2018), January and Gündüz (2006), the students regarded the concept of teachers as informative, gardener, sun, candle, mother, friend, guide, light source and parents. overlap. Again in similar studies, Turan, Ylldırım, and Clickman (2016), in their work, Guerro and Vilamil (2002), Küçüktepe and Gült (2014), Ekiz and Koçyiğit (2013), in which students give meaning to the concept of teacher such as candle, sun, light, information source and guidance., Özdemir (2018) 
and Koçbeker and Saban (2006) have also determined that they see the concept of teacher as a source of information for students. This is similar to the results of the study. It is a very good situation for the senior students in the undergraduate program studying at the Faculty of Education to have positive thoughts about the concept of teacher. Because social information teacher plays an important role in the development of children in the second level of primary education.

In Patchen and Crawford (2011), Çelikten (2006), Gillis and Johnson (2002) studies, it was observed that students attributed extraordinary meanings to the concept of teacher such as prophet, social insurance, mosque. These metaphors overlap with the metaphors determined in the current research. In addition, researches can be conducted with prospective teachers to compare the perceptions of teachers working on the concept of "teacher" through metaphors. In this process, it is thought that prospective teachers will provide positive benefits in terms of questioning themselves about the concept of teacher, creating teacher identity, developing and changing themselves.

Keywords: Social Studies Teacher, Teacher, Metaphor, Perception, Social Studies Teacher Candidate.

Özet: Yapılan bu araştırmada sosyal bilgiler öğretmen adaylarının öğretmen kavramına ilişkin algıları, bakış açıları, öznel görüşleri ortaya konmak istenmiş öğretmen kavramına yükledikleri anlamları ortaya koymak amaçlanmıştır. Bu amaçlarla yola çıkılan araştırmanın genel amacı, sosyal bilgiler öğretmen adaylarının öğretmen kavramına ilişkin algılarının metaforlar yoluyla incelenmesidir. Bu genel amaç doğrultusunda araştırmada şu sorulara cevap aranmıştır: Sosyal bilgiler öğretmen adaylarının öğretmen kavramına ilişkin sahip oldukları metaforlar nelerdir? Sosyal Bilgiler öğretmen adayları tarafından öğretmen kavramına ilişkin olarak ileri sürülen metaforlar ortak özellikleri bakımından hangi kategoriler altında toplanabilir? Araştırma yöntemsel olarak bir nitel bir araştırmadır. Araştırmanın çalışma grubunu Ege Üniversitesi Eğitim Fakültesi Sosyal Bilgiler Öğretmenliği Ana Bilim Dalı'nda 2019-2020 güz Döneminde okuyan ve araştırmaya katılmayı kabul eden gönüllü 41 son sınıf Sosyal bilgiler öğretmenliği öğrencileri oluşturmuştur. Araştırmada verileri toplamak için öğrencilere üzerinde "Öğretmen .........gibidir. Çünkü.........." ifadesi bulunan formlar dağıtılmış ve form üzerindeki ifadeyi tamamlamaları istenmiştir. Daha sonra öğrencilerin kendi ifadelerini yazdığı formlar toplanarak elde edilen veriler üzerinde içerik analizi yapılmıştır. Öğrenciler tarafından tamamlanan ifadeler incelenerek, gerekçeli açıklama yapmayan beş öğrencinin kâğıdı işlem dışı bırakılmıştır Verilerin çözümlemesi süreci adlandırma, eleme, kategorilendirme ve geçerlik ve güvenirliği sağlama olmak üzere dört aşamada gerçekleşmiştir. Verilerin çözümlemesi sonunda öğretmen adayları tarafindan oluşturulan 36 metafor üç kategorisel başlık altında toplanmıştır. Toplanan başlıklar yorumlanarak öğretmen kavramına ilişkin sosyal bilgiler öğretmen adaylarının motaforik bakış açıları ortaya konmaya çalışılmıştır.

Anahtar Kelimeler: Sosyal Bilgiler Öğretmenliği, Öğretmen, Metafor, Alg1, Sosyal Bilgiler Öğretmen Adayı.

\section{Giriş}

Öğretmenler, tartışmasız toplumumuzun en önemli ögelerinden biridir. Çocuklara bir amaç verir, onları iyi bir insan, ülkemiz için iyi bir vatandaş, meslek ve iş hayatında başarılı olma yolunda bir esin kaynağı olur. Öğretmenler, geleceğin liderlerini toplum için en iyi şekilde biçimlendirme, olumlu ve ilham verici geleceğe nesiller inşa etmede çok önemli bir rol oynamaktadırlar. Öğretmen, çocuğun aynı zamanda ikinci ebeveynidir. Bir öğrencinin hayatının çoğu kısmı okulda geçmektedir ve bu yüzden hayatını evde öğrenebildiği gibi çoğunlukla okulda da öğrenebilmektedir. Bu nedenle öğretmenin sadece ders kitaplarıyla bilgi vermesi değil aynı zamanda genel konularda da iyi bir ders vermesi bir öğretmenin görevi olmalıdır. Öğretmenler, ayrıca öğrencilerin sınırlarını genişletebilir ve yaratıcılıklarını zorlayabilir. Öğretmek zor bir iş olarak görülebilir; ancak öğretmenlik mesleği başka birinin hayatında çok fazla etkide bulunan bir meslektir.

Öğretmen, bilgiyi rafine ettikten sonra o bilginin öğrenciye ulaşmasında aracı olan kişidir. Öğrettiği bilgileri düzenleyerek aktarır. Öğrencinin öğrenip öğrenmediğini gözlemler ve onlara rehberlik ve danışmanlık yapar (Aydın, 2005, 26; Pala, 2006, 8). Öğretmen kavramı geçmiş zamandan çeşitli olarak artık yalnızca bilgi öğreten konumundan ele alınmamaktadır. Yeni anlayışa 
göre öğretmen öğrencinin yaşadığı çevreyi, ailesini, öğrenme için öğrencinin ekonomik ve sosyal çevresini bilen ve ona göre hareket edendir. Öğretmen öğrenciyi, tanıyarak, onun eğitim ve öğretimi için uygun şartları sağlayacaktır. Bunun yanında daha nitelikli eğitim- öğretim için öğrencinin gelişim ve öğrenme özellikleri ve öğrenmeyi etkileyen diğer faktörleri özenle inceleyerek ele alan eğitimdir (Kıncal, 2009; 35-36).

Okullarda öğrencilerin öğrenmelerini, gelişimlerini ve kişilik kazanmalarına tesir eden önemli unsurlardan biri öğretmendir. Eğitim sürecinin başarısı, sürdürülebilir olması ve nitelikli duruma gelmesinde öğretmenler önemli bir unsurdur (Altan, 2014). Günümüzde öğretmenlik mesleği öğretmen olan kimseler tarafından idame ettirilir. Öğretmen, mesleği öğretmek olan kişidir. Günümüzde öğretmen, öğretmenlik mesleğinin gerektirdiği yeterlikleri oluşturan lisans eğitimini

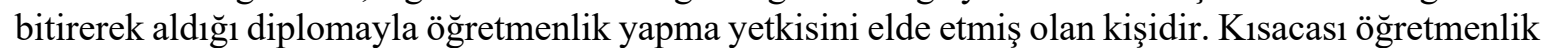
öncelikle öğretimcilik demektir. Ancak öğretmenlikte öğretme görevi ile sınırlı kalınmaz, kanaat k1lınmaz. Çünkü öğretme eğitme ile iç içe gerçekleşir. Böylece öğretmenlik daha geniş bir anlam kazanır. Bu anlamda öğretmenlik eğitmenliği de kapsar, içerir. Öyleyse öğretmenlik öğretme odaklı eğitimciliktir. Buna göre öğretmenlik mesleği öğretme odaklı bir eğitimcilik mesleğidir (Uçan, 2019). Bu yüzden soyut bir kavram olan öğretmenin anlaşılır bir şekilde tarif edilmesine aracılık edeceği düşünülen metafor, bir tür şeyi başka bir tür şeye göre anlamak ve tecrübe etmektir (Lakoff ve Johnson, 2005, s.27). Başka bir deyişle metafor somut, daha tanıdık ve görülebilir şeylerle soyut şeyler arasında kurulan mecazi bağ olarak da açıklanabilir (Saban, 2004).

Metaforlar karmaşık kavramlara ilişkin sezgisel bir bakışa sahip olmak ve bireylerin kişisel deneyimlerine ilişkin görüş edinmek açısından önem taşımaktadır. Metafor kelimesi kökenini Yunanca meta (arasında) ve pherein (taşımak) kelimelerinin birleşiminden meydana gelen 'metapherein' (aktarmak) kelimesinden almaktadır. Bundan dolayı metafor 'bir içeriğin bir şeyden başka bir şeye aktarımı' anlamına gelmektedir (Gibbs, 1994, s.210; Nikitina ve Furuoka, 2008, Akt; Konaklı ve Gögüss, 2013, s. 68).

Metaforlar kullananlara geniş bakış açıları sağlar. Kurulan metaforlar üzerindeki anlam aktarımları kavramlar arasındaki ilişki üzerinde düşülmesini sağlarken, diğer yandan çok belirgin olmayan, farklı özelliklerin ortaya çıkmasını da sağlar (Rundgren, Hirsch ve Tibell, 2009). Metaforlar, kavramların anlaşılmasını ve yorumlanmasını kolaylaştırarak, analiz edilmek istenilen kavramların nasıl algılandığını ortaya çıkarmaya katkı sağlarken (Cerit, 2008; Akt, Kasapoğlu 2016, s. 61), metafor analizi araştırmanın amacına bağlı olarak bireylerin konuşma ya da etkileşim sırasında kullandığ 1 anahtar kelime ve kavram üzerine derinlemesine yoğunlaşarak, bir konuya açıklık getirmek için bunların tespiti ve ne anlama geldiğiyle ilgilenir (Ekiz, 2009; Akt, Kasapoğlu 2016, s. 61). Son yıllarda ülkemizde sosyal bilimlerin çeşitli alanlarında metafor ile ilgili birçok araştırmaların olduğu görülmektedir (Balc1, 1999; Guerrero ve Villamil, 2000; Saban, 2004; Ocak ve Gündüz, 2006; Saban, Koçbeker ve Saban, 2006; Çelikten, 2006; Girmen, 2007; Semerci, 2007; Aydoğdu, 2008; Cerit, 2008; Arslan, 2008; Akar ve Y1ldırım, 2009; Oğuz, 2009; Kumral, 2009; Aydın ve Pehlivan, 2010; Saban, 2011; Güler, Öçal ve Akgün, 2011; Özdemir, 2012; Gültekin, 2013; Konakl1 ve Göğüş, 2013; Akbari, 2013; Demirtaş \& Çoban, 2014; Koç, 2014; Babacan, 2014; Mentiş- Köksoy, 2015; Aydıner- Uygun, 2015; Bahar- Güner ve diğerleri, 2015; Acay-Sözbir ve Çamlıbel- Çakmak, 2016; Tez, Aydıner- Uygun, 2016; Eren, 2018; Mentiş-Köksoy, 2017; Özaydın, 2019). Gelecek nesilleri yetiştiren öğretmenlerin, öğretmen adaylarına rol model oldukları göz önünde bulundurulduğunda "öğretmen" kavramını nasıl algıladıklarının belirlenmesi önemli görülmektedir. Öğrencilerin öğretmenlerini rol model aldıkları varsayımdan yola çıkacak olursak öğrencinin ilgi, istek ve yeteneklerine daha yakın branştaki öğretmenleri rol model almaları yadsınamaz bir gerçektir. Sosyal bilgiler branş olarak günlük yaşamla daha ilişkili ve sosyal iletişim etkinlikleri bol olan bir ders olduğu için öğrencilerin sosyal bilgiler öğretmenlerini algılamaları 
farklılık gösterecektir. Bu bağlamda araştırmada sosyal bilgiler öğretmen adaylarının "öğretmen" kavramına ilişkin algılarının metaforlar yoluyla belirlenmesi amaçlanmıştır.

$\mathrm{Bu}$ genel amaç doğrultusunda bu çalışmada şu sorulara cevap aranmıştır.

1. Sosyal bilgiler öğretmen adaylarının öğretmen kavramına ilişkin sahip oldukları metaforlar nelerdir?

2. Sosyal bilgiler öğretmen adayları tarafından öğretmen kavramına ilişkin olarak ileri sürülen metaforlar ortak özellikleri bakımından hangi kategoriler altında toplanabilir?

\section{Yöntem}

\section{Araştırma Modeli}

$\mathrm{Bu}$ araştırmada nitel araştırma yöntemlerinden olan olgubilim (fenomenoloji) deseni kullanılmıştır. Olgubilim deseni, farkında olduğumuz fakat yoğunlamasına ve detaylı bir düşünceye sahip olmadığımız olgulara odaklaşmaktadır. Bize tamamiyle yabancı olmayan fakat tam anlamını kavrayamadığımız olguları araştırmayı hedefleyen çalışmalar için olgubilim elverişli bir araştırma temeli oluşturur. Olgubilim çalışmalarında çoğunlukla bir olguya ilişkin bireysel algıların ortaya çıkarılması ve yorumlanması amaçlanır ( Yıldırım ve Şimşek, 2008). Bu doğrultuda sosyal bilgiler öğretmen adaylarının öğretmen kavramına ilişkin ileri sürdükleri metaforlar ortaya çıkarılarak yorumlanmıştır.

\section{Çalışma Grubu}

Araştırmanın çalışma grubunu 2019-2020 güz döneminde Ege Üniversitesi, Eğitim Fakültesi Sosyal Bilgiler Öğretmenliği Anabilim Dalı'nda okuyan 41 son sınıf öğrencisi oluşturmuştur. Çalışma grubunun oluşturulmasında kolay ulaşılabilir durum örnekleme yöntemi kullanılmıştır. Bu örnekleme yöntemi araştırmaya hız ve zaman kazandırır. Çünkü bu yöntemde araştırmacı, yakın olan ve erişilmesi kolay olan bir durumu seçer. Kolay ulaşlabilir durum örneklemesi çoğu zaman araştırmacının diğer örnekleme yöntemlerini kullanma olanağının bulunmadığı durumlarda kullanılır (Yıldırım ve Şimşek, 2006, s. 113).

\section{Verilerin Toplanması}

Sosyal bilgiler öğretmen adaylarının "Öğretmen” kavramıyla ilgili metaforlarını belirlemek için katılımcılara üzerinde "Öğretmen ... gibidir. Çünkü ... “ ifadesi bulunan formlar dağıtılmış ve form üzerindeki ifadeyi tamamlamaları istenmiştir. Çalışmanın başında öğretmen adaylarına "metafor" kavramının ne olduğu örneklerle açıklanmış ve bu cümleye uygun metafor üretmeleri ve neden bu metaforu tercih etme sebeplerini yazmaları için de 20 dakika süre verilmiştir. Bu çalışmada öğretmen adaylarının kafalarında tasarladıkları ilk metaforlara odaklanmaları hedeflendiği için bu sürenin uygun olacağı düşünülmüştür. Öğretmen adaylarının yukarıda bahsedilen cümleye verdikleri yanıtlar araştırmamızın temel veri tabanını oluşturmuştur.

\section{Verilerin Analizi}

Verilerin çözümlemesi süreci adlandırma, eleme, kategorilendirme ve geçerlik ve güvenirliği sağlama olmak üzere dört aşamada gerçekleşmiştir (Saban, 2008). Verilerin çözümlemesinde öğrenciler tarafindan doldurulan formlar Ö1, Ö2 (Öğrenci1, Öğrenci2) şeklinde numaralandırılmıştır. Öğrencilerin ürettikleri metaforlar numaraya göre kodlanmıştır. İkinci aşamada öğrenciler tarafından tamamlanan ifadeler incelenerek gerekçeli açıklama yapmayan beş öğrencinin kâğıdı işlem dışı bırakılmıştır. Gerekçelendirilerek açıklama yapılmış geçerli 36 metafor elde edilmiştir. Üçüncü aşamada öğrenciler tarafindan tamamlanan ifadeler tekrar gözden geçirilmiştir. Öğrenciler tarafından oluşturulan metaforlar ortak özellikleri bakımından incelenmiştir. Geçerli 36 metafor ortak özellikleri bakımından ve gerekçelendirilme sebepleri dikkate alınarak üç kategori altında toplanmıştır. Dördüncü aşamada araştırma sonuçlarının geçerliğini sağlamak amacıyla veri 
analizi sürecinin nasıl yürütüldüğü açıklanmış ve araştırmada elde edilen metaforlara yer verilmiştir. Ayrıca bulgular kısmında 36 metafora ilişsin oluşturulan 3 kategorinin her birini en iyi ifade ettiği düşünülen örneklere yer verilmiştir. Araştırmanın güvenilirliğini sağlamak içinse üç kategori altında yer alan metaforların söz konusu kategoriler altında toplanıp toplanmadığını belirlemek amacıyla araştırmacının iki ayrı zamanda yaptı̆̆ kodlamalardaki tutarlılık incelenmiştir. Bunun için araştırmacı 15 gün arayla ikinci defa kodlama yapmış ve kendi tutarlılığını sınamıştır. Güvenirlik=görüş birliği/görüş birliği + görüş ayrıllğı formülü (Miles ve Huberman,1994) kullanılmış ve tutarlılığın kodlama güvenirlik katsayısı .90 olarak hesaplanmıştır.

\section{Bulgular ve Yorumlar}

Araştırma verilerinin analizi sonucunda elde edilen veriler doğrultusunda sosyal bilgiler öğretmen adaylarının "öğretmen” kavramına ilişkin metaforları Tablo 1'de gösterilmiştir.

Tablo1- Sosyal bilgiler öğretmen adaylarının öğretmen kavramına ilişkin ileri sürdükleri metaforlar

\begin{tabular}{lclc}
\hline Metafor & $\mathbf{n}$ & Metafor & $\mathbf{n}$ \\
\hline ağaç & 1 & nar & 1 \\
atmosfer & 2 & anne & 3 \\
fener & 2 & aile & 1 \\
Google & 1 & bilgisayar & 1 \\
yanan bir mum & 3 & papatya & 1 \\
güneş & 2 & çikolatalı pasta & 1 \\
turist rehberi & 1 & okyanus & 1 \\
kitap & 1 & matruşka bebek & 1 \\
roman & 1 & marangoz & 1 \\
fabrika & 1 & mutfak robotu & 1 \\
dikiş makinası & 1 & yer-yön levhaları & 1 \\
çiftçi & 3 & bir harita & 1 \\
tavuk & 1 & bahçıan & 1 \\
trafik levhaları & 1 & &
\end{tabular}

\section{Toplam $\quad 36$}

Tablo 1 incelendiğinde öğretmen adaylarının metafor kavramına ilişkin 36 metafor ürettikleri görülmektedir. Öğretmen adayları öğretmen kavramını en çok yanan bir mum (3), çiftçi (3), anne (3), atmosfer (2), fener (2), güneş (2) metaforlarına benzettikleri görülmektedir. Öğretmen adaylarının çoğunlukla 1şı, yol gösteren ve şefkat veren olarak algıladıkları söylenebilir. Öğretmen adaylarının öğretmen kavramını ağaç, Google, turist rehberi, kitap, roman, fabrika, dikiş makinesi, tavuk, trafik levhaları, nar, aile, bilgisayar, papatya, çikolatalı pasta, okyanus, matruşka bebek, marangoz, mutfak robotu, yer yön levhaları, bir harita ve bahçıvan metaforları ile özdeşleştirdikleri saptanmıştır.

Sosyal bilgiler öğretmen adaylarının öğretmen kavramına ilişkin oluşturdukları metaforlar kategorileştirilerek tablo 2'de gösterilmiştir. 


\begin{tabular}{lrl}
\multicolumn{3}{c}{ Tablo 2-Metaforlara ilişkin kategoriler } \\
\hline Kategori & n & \% \\
\hline Aydınlatan & 13 & 36,11 \\
Şekil, Yön ve Emek veren & 15 & 41,60 \\
Tat ve Huzur Veren & 8 & 22,20 \\
& & \\
\hline Toplam & 36 & 100 \\
\hline
\end{tabular}

Tablo 2 incelendiğinde sosyal bilgiler öğretmen adaylarının oluşturduğu metaforların üç kategoride toplandığı görülmektedir. Öğretmen adayları tarafından oluşturulan metaforların \%36,11 $(n=13)$ aydınlatan, \%41,60 $(n=15)$ şekil, yön ve emek veren, $\% 22,20(n=8)$ tat ve huzur veren kategorilerinde yer aldıkları görülmektedir. Sosyal bilgiler öğretmen adaylarının oluş̧urdukları metaforlar sonucunda oluşturulan kategorilere göre öğretmen kavramının en çok şekil, yön ve emek veren, aydınlatan, tat ve huzur veren olarak algılandığı söylenebilir.

Sosyal bilgiler öğretmen adaylarının aydınlatan kategorisine ilişkin oluşturdukları metaforlar tablo 3'de verilmiştir.

Tablo 3- Aydinlatan

\begin{tabular}{ll}
\hline Metafor & n \\
\hline Atmosfer & 2 \\
Fener & 2 \\
Google & 1 \\
Yanan bir Mum & 3 \\
Günes & 2 \\
Turist Rehberi & 1 \\
Kitap & 1 \\
Roman & 1 \\
& \\
\hline Toplam & 13 \\
\hline
\end{tabular}

Tablo 3'te yer alan metaforlar sosyal bilgiler öğretmen adayları tarafindan ileri sürülen gerekçeler dikkate alınarak Aydınlatan Kategorisinde en çok yanan bir mum $(n=3)$, atmosfer $(n=2)$, güneş $(n=2)$, fener $(n=2)$, turist rehberi $(n=1)$, Google $(n=1)$, kitap $(n=1)$, roman $(n=1)$ metaforlarını da aydınlatan kategorisinde ürettikleri görülmektedir. Sosyal bilgiler öğretmen adaylarının aydınlatan kategorisinde ürettikleri metaforlara ilişkin görüşlerinden bazıları, doğrudan alıntı şeklinde aşağıda verilmiştir.

"Öğretmen atmosfer gibidir. Çünkü yararlı bilgileri bize ögrretirken bizim için zararlı olabilecek bilgilerden arındirır, uzak tutar" (ÖA.4).

Öğretmen fener gibidir. Çünkü öğrenci yapabileceklerini onun ışı̆̆ının yardımıyla farkına varabilir (ÖA.7).

Öğretmen Google gibidir. Çünkü her şeyi bilir veya yönlendirir (ÖA15).

Öğretmen yanan bir mum gibidir. Çünkü henüz alev olmamış tüm mumlara yani ögrencilerine ateş olur, tecrübe ve bilgilerini aktarır. Mumu eridikçe yani ögretmen ne kadar çok çocuğa dokunursa o kadar tabana yayılır ve birçok alan bundan etkilenir (ÖA.27)

Öğretmen bir güneş gibidir. Çünkü öğrencilerine ışık saçar (ÖA.29) (ÖA.30).

Öğretmen bir turist rehberi gibidir. Çünkü bilmedikleri bir ortamda ögrencilere yol gösterir

Sosyal bilgiler öğretmen adaylarının şekil, yön ve emek veren kategorisine ilişkin oluşturdukları metaforlar tablo 4 de verilmiştir. 
Tablo 4- Şekil, yön ve emek veren

\begin{tabular}{ll}
\hline Metafor & n \\
\hline Fabrika & 1 \\
Dikiş Makinası & 1 \\
Çiftçi & 3 \\
Tavuk & 1 \\
Marangoz & 1 \\
Trafik Levhaları & 1 \\
Yer-yön Tabelası & 1 \\
Bir harita & 1 \\
Bahçıvan & 1 \\
Matruşka Bebek & 1 \\
Mutfak Robotu & 1 \\
Nar & 1 \\
Ağaç & 1 \\
\hline Toplam & 15 \\
\hline
\end{tabular}

Tablo 4 incelendiğinde şekil, yön ve emek veren kategorisinde fabrika $(\mathrm{n}=1)$, dikiş makinesi $(n=1)$, çiftçi $(n=3)$, tavuk $(n=1)$, marangoz $(n=1)$, trafik levhaları $(n=1)$, yer- yön tabelası $(n=1)$, bir harita $(n=1)$, bahçıvan $(n=1)$, matruşka bebek $(n=1)$, mutfak robotu $(n=1)$, nar $(n=1)$, ağaç $(n=1)$ metaforlarını da şekil yön ve emek veren kategorisinde ürettikleri görülmektedir. Sosyal bilglier öğretmen adaylarının şekil yön ve emek veren kategorisinde ürettikleri metaforlara ilişkin görüşlerinden bazıları doğrudan alıntı şeklinde aşağıda verilmiştir.

Fabrikaya gelip nasll yepyeni bir ürün oluşturuyorsa, ögrencilerde öğretmenden geçecek yeni, korumal, bir amaca hizmet eden kişilere dönüşecek (ÖA.2).

Öğretmen matruşka bebek gibidir. Çünkü bilgeliği, sabrı ve bunlara yönelik tüm tavırları bitmez, her an yenilenir ve katlanır (ÖA.3).

Öğretmen tavuk gibidir. Çünkü tavuklarda civcivleri büyüyüp güçleninceye kadar onlara yardımcı olurlar ve civcivleri onları takip eder (ÖA.1).

Öğretmen trafik levhaları gibidir. Çünkü öğrencilere yol gösterir ve nerede, nasıl, ne yapılması gerektiği hakkında yalnızca yönlendirmeler yapabilir, tercih ögrencilerindir (ÖA.19).

Öğretmen çiftçi gibidir. Çünkü çiftçi nasıl ham meyveler için farklı tohum kullanıp güzel meyveler elde etmeyi amaçlar ise ögretmen de her ögrenciye farkl yollarla ulaşır ve onlar en iyi şekilde yetiştirmeyi amaçlar (ÖA.20).

Öğretmen yer-yön tabelası gibidir. Çünkü ögrenciye rehberlik eder. Hayatına şekil vermesinde, düşüncelerin oluşmasında yol gösterir, hedefe ulaşmayı sağlar (ÖA.21).

Öğretmen mutfak robotu gibidir. Çünkü mutfaktaki değişik malzemeleri bir araya getirerek ögütür ve bireysel farkları birleştirerek ortaya yeni tatlar çıkartır (ÖA.26).

Sosyal bilgiler öğretmen adaylarının tat ve huzur veren kategorisine ilişkin oluşturdukları metaforlar tablo 5'de verilmiştir. 
Tablo 5- Tat ve huzur veren

\begin{tabular}{ll}
\hline Metafor & n \\
\hline Anne & 3 \\
Aile & 1 \\
Çikolatalı Pasta & 1 \\
Papatya & 1 \\
Bilgisayar & 1 \\
Okyanus & 1 \\
\hline Toplam & 8 \\
\hline
\end{tabular}

Tablo 5 incelendiğinde tat ve huzur veren kategorisinde en çok anne $(n=3)$, aile $(n=1)$, çikolatalı pasta $(\mathrm{n}=1)$, papatya $(\mathrm{n}=1)$, bilgisayar $(\mathrm{n}=1)$, okyanus $(\mathrm{n}=1)$ metaforlarını da tat ve huzur veren kategorisinde ürettikleri görülmektedir. Öğretmen adaylarının tat ve huzur veren kategorisinde ürettikleri metaforlara ilişkin görüşlerinden bazılar doğrudan alıntı şeklinde aşağıda verilmiştir.

Öğretmen bilgisayar gibidir. Çünkü insanlar bilgisayardan aynı öğretmenden aldı̆̆ gibi istediği zaman bilgi alır. Almak istemiyorsa öğretmen ne kadar bilirse bilsin öğrenci ögrenemez. Öğretmenin de bilgisi bilgisayar gibi sinırlıdır. Ancak kendini geliştirirse aynı bilgisayar gibi bilgileri çoğalır (ÖA.9) (ÖA.42).

Öğretmen aile gibidir. Çünkü içerisinde gerçek bir çocuk sevgisi ve merhamet vardır

Öğretmen anne gibidir. Çünkü şefkatli ve koruyucudur (ÖA.16).

Öğretmen çikolatalı pasta gibidir. Çünkü ondaki bilgileri tattıkça mutluluk verir (ÖA.14).

Öğretmen papatya gibidir. Çünkü beyaz birçok yaprağı vardır ve her bir yaprăğ kopardıkça her yapraktan farklı bir yön, bilgi, beceri çıkar ve tüm hepsi bir gövde üzerinde toplanmıștır (ÖA.22). (ÖA.35).

Öğretmen okyanus gibidir. Çünkü okyanus gibi içerisinde tüm güzellikleri barındırır.

\section{Sonuç, Tartışma ve Öneriler}

Sosyal bilgiler öğretmen adayları öğretmen kavramına ilişkin 36 metafor üretmişlerdir. $\mathrm{Bu}$ metaforlar aydınlatan, şekil/yön ve emek veren, tat ve huzur veren başlıkları altında 3 kategori altında toplanmıştır. Bu bulgulara dayalı olarak sosyal bilgiler öğretmen adaylarının öğretmen kavramını yaşamlarında önemli gördükleri ve öğretmen kavramına çok olumlu anlamlar yükledikleri söylenebilir. Çalışmada ortaya çıkan sonuçlar Sosyal Bilgiler Öğretmen adaylarının öğretmen kavramını çoğunlukla fener, yanan bir mum, güneş, kitap, roman, bilgi kaynağı, turist rehberi, marangoz, anne, yer yön tabelası olarak algıladıkları görülmüştür. Ertürk (2017), çalışmasında öğrencilerin öğretmenlerini anne- baba metaforuyla açıkladıkları, Saban (2004) tarafından yapılan çalışmanın soncunda öğretmen adaylarının öğretmenleri bir heykeltraş olarak gördükleri, Çelikten (2006), Gillis ve Jonhson (2002), Cerit (2008), Turhan ve Yaraş (2013) çalışmalarının sonuçlarına göre öğretmen kavramını çiftçi, bahçıvan, ağaç, Google, bilgisayar, 1şık, fener, kitap gibi bilinen metaforlarla açıklamaları bu çalışmanın sonuçlarıyla benzerlik göstermektedir. Saban (2006), çalışmasında öğrencilerin öğretmen kavramını bilgi kaynağı olarak nitelemeleri, Aydın ve Pehlivan (2010) çalışmalarında öğrencilerin öğretmeni bilgi kaynağı olarak gördükleri, Koç (2014), çalışmasında öğretmen kavramını bilgi kaynağı ve fedakâr olarak görmeleri, Kalyoncu (2012), çalışmasında da öğretmen kavramına öğrencilerin eğitici, öğretici ve yol gösterici olarak anlam yükledikleri görülmüştür. Yıldırım, Ünal ve Çelik (2011), Özdemir (2018), Ocak ve Gündüz (2006) çalışmalarında da öğretmen kavramına öğrencilerin bilgilendirici, bahçıvan, güneş, mum, anne, arkadaş, rehber, 1şık kaynağı ve anne- baba olarak görmeleri bu çalışmanın sonuçlarıyla örtüşmektedir. Yine benzer çalışmalarda Turan, Yıldırım ve T1kman (2016) yaptıkları çalışmalarında 
öğretmen kavramına öğrencilerin mum, güneş, 1şık, bilgi kaynağı, yol gösterici gibi anlamlar yükledikleri Guerro ve Vilamil (2002), Küçüktepe ve Gürültü (2014), Ekiz ve Koçyiğit (2013), Özdemir (2018) ve Koçbeker ve Saban (2006) çalışmalarında da öğretmen kavramını öğrencilerin bilgi kaynağı olarak gördükleri belirlenmiştir. Bu da yapılan çalışmanın sonuçlarıyla benzerlik göstermektedir. Eğitim Fakültesinde öğrenim görmekte olan lisans programındaki son sınıf öğrencilerinin öğretmen kavramı hakkında olumlu düşünceler için de olmaları son derece güzel bir durumdur. Çünkü Sosyal blgiler öğretmeni ilköğretim ikinci kademesinde çocukların gelişiminde önemli bir rol oynar.

Patchen ve Crawford (2011), Çelikten (2006), Gillis ve Johnson (2002) çalışmalarında öğrencilerin öğretmen kavramına peygamber, sosyal sigorta, cami gibi sıra dışı anlamlar yükledikleri görülmüştür. Bu metaforlar eldeki araştırmada belirlenen metaforlarla örtüşmektedir.

Eğitim Fakültesindeki öğrenim görmekte olan farklı branşlardaki adayların görüşlerine başvurularak bölümler arası uygulamalar yapılarak karşılaştırma yapılabilir. Araştırmada öğretmen adaylarının vermiş oldukları cevaplara göre ortaya çıkan temalardan yararlanarak yeni çalışmalar yapılabilir. Farklı ölçek geliştirme çalışmaları yapılabilir. Bunun sonuncunda öğretmenlerin değerlendirilmesi amacıyla daha geniş kitlelere ulaşarak daha net sonuçlara ulaşılması sağlanabilir.

Ayrıca öğretmen adaylarıyla, görev yapan öğretmenlere "öğretmen” kavramına ilişkin algılarının metaforlar aracılığıyla karşılaştırılmasını ele alacak araştırmalar yapılabilir. Bu da ilerleyen süreçte öğretmen adaylarının öğretmen kavramına ilişkin kendilerini sorgulama, öğretmen kimliği oluşturma, kendilerini geliştirme ve değiştirme açısından olumlu faydalar sağlayacağı düşünülmektedir.

\section{Kaynakça}

Acay-Sözbir, S. ve Çamlıbel-Çakmak, Ö. (2016). Okul öncesi öğretmen adaylarının "müzik" kavramına ilişkin metaforik algıları. The Jour-nal of Academic Social Science Studies, 42, 269-282.

Akbari, M. (2013). Metaphors about EFL teachers' roles: A case of Iranian non-english major students. IJ- ELTS: International Journal of English Language \& Translation Studies, $1(2), 100-112$.

Akar, H., \& Yıldırım, A. (2009). Change in teacher candidates' metaphorical images about classroom management in a social constructivist learning environment. Teaching in Higher Education, 14(4), 401-415. Altan, M. Z. (2014). Türkiye'nin eğitim çıkmazı: Girişimci öğretim girişimci öğretmen. Ankara: Pegem Akademi Yayıncılık.

Altan, M. Z. (2014). Türkiye'nin eğitim çıkmazı: Girişimci öğretim girişimci öğretmen. Ankara: Pegem Akademi Yayıncilık.

Arslan, F. (2008). Metaforik tercihler bakımından Akif'i okuyabilmek. I. Uluslararası Mehmet Akif Sempozyumu, 259, Mehmet Akif Ersoy Üniversitesi.

Aydın, M. Şevki (2005). Cumhuriyet Döneminde Din Eğitimi Öğretmeni Yetiştirme ve İstihdamı. İstanbul: Dem Yayınları

Aydın, İ. S., \& Pehlivan, A. (2010). Türkçe öğretmeni adaylarının öğretmen ve öğrenci kavramlarına ilişkin kullandıkları metaforlar. Turkish Studies, 5(3), 818-842. 
Aydıner-Uygun, M. (2015). Öğretmen adaylarının geleneksel müzik türlerine ilişkin algılarının metaforlar aracılığıla incelenmesi. Afyon Kocatepe Üniversitesi Akademik Müzik Araştırmaları Dergisi, 1(1), 59-76.

Aydoğdu, E. (2008). İlköğretim okullarındaki öğrenci ve öğretmenlerin sahip oldukları okul algıları ile ideal okul algılarının metaforlar yardımıyla analizi. Unpublished master's thesis, Eskişehir Osmangazi Üniversitesi, Eskişehir.

Babacan, E. (2014). AGSL öğrencilerinin müzik kavramına ilişkin algıları: Metafor analizi. Eğitim ve Öğretim Araştırmaları Dergisi, 3(1), 124-132. Babacan, E. (2014). AGSL öğrencilerinin müzik kavramına ilişkin algıları: Metafor analizi. Eğitim ve Öğretim Araştırmaları Dergisi, 3(1), 124-132.

Bahar-Güner, Ö., Tunca, N., Alkın-Şahin, S., \& Oğuz, A. (2015). Öğretmen adaylarının öğretmen eğitimcisine ilişkin metaforik algıları. Pegem Eğitim ve Öğretim Dergisi, 5(4), 419-444.

Balc1, A. (1999). Metaphorical images of school: School perceptions of students, teachers, and parents from four selected schools (in Ankara). Unpublished doctorate dissertation, Orta Doğu Teknik Üniversitesi, Ankara.

Cerit, Y. (2008). Öğretmen kavramı ile ilgili metaforlara ilişkin öğrenci, öğretmen ve yöneticilerin görüşleri. Türk Eğitim Bilimleri Dergisi, 6(4), 693-712.

Çelikten, M. (2006). Kültür ve öğretmen metaforları. Erciyes Üniversitesi Sosyal Bilimler Enstitüsü Dergisi, 21(2), 269-283.

Demirtaş, H., \& Çoban, D. (2014). Üniversite öğrencilerinin öğretim elemanlarına ilişkin metaforları. Kastamonu Eğitim Dergisi, 22(3), 1279-1300.

Ekiz, D. ve Koçyiğit, Z. (2013). Sınıf öğretmenlerinin öğretmen kavramına ilişkin metaforlarının belirlenmesi, Kastamonu Eğitim Dergisi, 21(2), 439-458.

Eren, B. (2018). Özel eğitim öğretmeni adaylarının "müzik" kavramına ilişkin metaforik algıları. Turkish Studies Educational Sciences,13/19(Summer 2018), 697-716.

Ertürk, R. (2017). İlkokul öğrencilerinin öğretmen kavramına ilişkin metaforik algıları. EUluslararası Ĕgitim Araştırmaları Dergisi, 8 (3), 1-5. DOI: 10.19160/ijer.285232

Gillis, C. ve Johnson, C. L. (2002). Metaphor as renewal: re-imagining our professional selves. The English Journal, 91(6), 37-43.

Girmen, P. (2007). İlköğretim Öğrencilerinin Konuşma ve Yazma Sürecinde Metaforlardan Yararlanma Durumları. (Yayımlanmamış Doktora Tezi). Anadolu Üniversitesi Eğitim Bilimleri Enstitüsü, Eskişehir.

Guerrero, M. C. M., \& Villamil, O. S. (2000). Exploring ESL teachers' roles through metaphor analysis. TESOL Quarterly, 34(2), 341-351.

Guerrero, M. C. M. ve Villamil, O. S. (2002). Metaphorical conceptualizations of ESL teaching and learning. Language Teaching Research, 6(2), 95-120.

Güler, G., Öçal, M. F., \& Akgün, L. (2011). Pre-service mathematics teachers' metaphors about mathematics teacher concept. Procedia Social and Behavioral Sciences, 15, 327-330.

Gültekin, M. (2013). İlköğretim öğretmen adaylarının eğitim programı kavramına yükledikleri metaforlar. Eğitim ve Bilim, 38(169), 126-141. 
Kalyoncu, R. (2012). Görsel Sanatlar Öğretmeni Adaylarının “Öğretmenlik” Kavramına İlişkin Metaforları . Mustafa Kemal Üniversitesi Sosyal Bilimler Enstitüsü Dergisi 9, (20), s. 471484.

Kasapoğlu, H. (2016). Öğretmen adaylarının Türk Eğitim Sistemine ilişkin algılarının metaforlar yoluyla analizi. Kuram ve Uygulamada Eğitim Yönetimi, 22(1), 59-80. doi: 10.14527/kuey.2016.003

Koç, E. S. (2014). Sınıf öğretmeni adaylarının öğretmen ve öğretmenlik mesleği kavramlarına ilişkin metaforik algıları. İnönü Üniversitesi Eğitim Fakültesi Dergisi, 15(1).

Konaklı, T., Göğüş, N. (2013). Öğretmen adaylarının eğitim fakültesine ilişkin metaforik algıları: Kocaeli Üniversitesi Eğitim Fakültesi örneği. International Journal of Human Sciences, 10(2), 67-93.

Kumral, O. (2009). Öğretmen adaylarının öğretim elemanlarının davranışlarına yönelik algıları. Pamukkale Üniversitesi Eğitim Fakültesi Dergisi, 1(25), 92-102.

Küçüktepe, S. E. ve Gürültü, E. (2014). Öğretmenlerin “yapılandırmacı öğretmen” kavramına ilişkin algılarına yönelik metafor çalışması örneği. Abant İzzet Baysal Üniversitesi Eğitim Fakültesi Dergisi, 14(2), 282-305.

Kıncal, Remzi Y (2009). Eğitim Bilimine Giriş. Ankara: Nobel Yayınları.

Lakoff, G., \& Johnson, M. (2005). Metaforlar: Hayat, anlam ve dil. İstanbul: Paradigma Yayıncılık.

Mentiş-Köksoy, A. (2015). Primary school teacher candidates' perceptions related to the concept of music. International Review of Social Sciences and Humanities, 9(2), 9-15.

Mentiş- Köksoy, A. (2017). Preschool teacher candidates' metaphoric perceptions about the concept of music, Turkısh Onlıne Journal Of Educatıonal Technology, Ss.749-754.

Miles, MB. \& Huberman, AM. (1994). Qualitative Data Analysis (2nd edition). Thousand Oaks, CA: Sage Publications.

Mustan Dönmez, B. ve Karaburun, D. (2013). “Türk Halk Müziği Sözlerinde Metaforik Anlatım Geleneği”. Turkish Studies - International Periodical For The Languages, Literature and History of Turkish or Turkic 8 (4), 1081-1097.

Nikitina, L. \& Furuoka, F. (2008). Measuring Metaphors: A Factor Analysis of Students' Conceptions of Language Teachers. Metaphoric.de, 15, 161-180.

Ocak, G., \& Gündüz, M. (2006). Eğitim fakültesini yeni kazanan öğretmen adaylarının öğretmenlik mesleğine giriş dersini almadan önce ve aldıktan sonra öğretmenlik mesleği hakkındaki metaforlarının karşılaştırılması. Afyon Kocatepe Üniversitesi Sosyal Bilimler Dergisi, 8, 293-311.

Oğuz, A. (2009).Öğretmen adaylarına göre ortaöğretim öğretmenlerini temsil eden metaforlar. Milli Eğitim, 38(182), 36-57.

Özaydın, N. (2019). Müzik öğretmen adaylarının “ses” kavramına ilişkin metaforları. OPUSUluslararası Toplum Araştırmaları Dergisi,13(19), 332-358.

Özdemir, S. M. (2012). Eğitim programı kavramına ilişkin öğretmen adaylarının metaforik algıları. Kuramsal Eğitim Bilimleri Dergisi, 5(3), 369-393.

Özdemir, S. (2018). Üniversite Öğrencilerin Öğretmen Kavramına İlişkin Metaforik Algıları, Uluslararası Sosyal araştırmalar Dergisi, Cilt, 11 sayı. 59. 
Pala, Aynur (2006). Eğitimin Temel Kavramları. Eğitim Bilimine Giriş, Editör: Mustafa Yılman. Ankara: Nobel yayınları, ss.1-8

Patchen, T. ve Crawford, T. (2011). From gardeners to tour guides: The epistemological struggle revealed in teacher-generated metaphors of teaching. Journal of Teacher Education, 62(3), 286-298.

Rundgren, C. J., Hirsch, R., \& Tibell, L. A. E., (2009). Death of Metaphors in Life Science? - A study of upper secondary and tertiary students' use of metaphors in their meaning-making of scientific content, Asia-Pacific Forum on Science Learning and Teaching, 10(1).

Saban, A. (2004). Giriş düzeyindeki sınıf öğretmeni adaylarının "öğretmen" kavramına ilişkin ileri sürdükleri metaforlar. Türk Eğitim Bilimleri Dergisi, 2 (2), 131-155.

Saban, A., Koçbeker, B. N., \& Saban, A. (2006). Öğretmen adaylarının öğretmen kavramına ilişkin algılarının metafor analizi yoluyla incelenmesi. Kuram ve Uygulamada Eğitim Bilimleri, 6(2), 461-522.

Saban, A. (2008). İlköğretim I. kademe öğretmen ve öğrencilerinin bilgi kavramına ilişkin sahip oldukları zihinsel imgeler. İlköğretim Online, 7(2), 421-455.

Saban, A. (2011). Bilgisayar öğretmeni adaylarının “okul” ve "bilgisayar öğretmeni” kavramlarına ilişkin zihinsel imgeleri. Kuram ve Uygulamada Eğitim Bilimleri, 11(1), 423-446.

Semerci, Ç. (2007). Program geliştirme kavramına ilişkin metaforlarla yeni ilköğretim programlarına farklı bir bakış. Cumhuriyet Üniversitesi Sosyal Bilimler Dergisi, 31(2), 125-140.

Tez, İ., Aydıner-Uygun, M. (2016). Ortaokul öğrencilerinin müzik dersi ve müzik öğretmenine ilişkin algılarının metaforik analizi. Kalem Eğitim ve İnsan Bilimleri Dergisi, 6 (2), 417-455

Turan, M., Yıldırım, E. ve T1kman, (2016). Öğretmen adaylarının eğitim ve bazı temel kavramlara ilişkin metaforik algıları, M.Education Sciences (NWSAES), 11(4), 217-242.

Turhan, M. ve Yaraş, Z. (2013). Lisansüstü programların öğretmen, yönetici ve denetmenlerin mesleki gelişimine katkısı. Elektronik Sosyal Bilimler Dergisi, 12(43), 200-218.

Uçan A., (2019). http://www.ogretmen.info/ogretmenllk_tarIhce_.asp

Yıldırım, A\& Şimşek, H(2006). Sosyal bilimlerde nitel araştırma Yöntemleri, Seçkin Yayıncılık, Ankara

Yıldırım, A. ve Şimşek, H. (2008). Sosyal bilimlerde nitel araştırma yöntemleri. Ankara: Seçkin Yayıncilik.

Yıldırım, A., Ünal,. A., ve Çelik, M. (2011). Öğretmen Kavramına İlişkin Öğretmen, yönetici ve müfettiş algılarının analizi. Uluslararası İnsan Bilimleri Dergisi, 8, (2).

Yılmaz, F., Göçen, S. ve Yılmaz, F. (2013). Öğretmen adaylarının öğretmen kavramına ilişkin algıları: bir metaforik çalışma. Mersin Üniversitesi Eğitim Fakültesi Dergisi, 1(9), 161-164 